\title{
Time, Power and Environmental Impact: A Growth Curve Model of the Relationship Between Temporal Change and $\mathrm{CO}_{2}$ Emissions Per Capita
}

\author{
Patrick Trent Greiner' \\ Department of Sociology, Vanderbilt University \\ Tennessee, United States
}

\section{Abstract}

In this analysis, I examine the effect of social-structural factors associated with the passage of time on carbon dioxide $\left(\mathrm{CO}_{2}\right)$ per capita, while also accounting for global power relations. I use World Development Indicator data on 91 nations over a 60year period. I control for global power relations using Clark and Beckfield's (2009) trichotomous world-system categories to assign each country to a world-system stratum. I then use a hierarchical linear growth curve model to highlight the extent to which countries belonging to core, semi-periphery, and periphery categories are able to rely upon changes captured by the passage of time, such as improvements in technology, to reduce $\mathrm{CO}_{2}$ emissions per capita. Key findings indicate that, in nations belonging to the core and semi-periphery, such factors are associated with increases in $\mathrm{CO}_{2}$ emissions per capita, rather than the decreases that might be expected.

Keywords: carbon dioxide emissions; environmental sociology; structural human ecology

\section{Introduction}

It is often implicitly assumed by national governments and international organizations that, over time, there is a linear progression in both technological efficiency and ecological awareness among populations, producers, and policymakers that leads to a general decline in negative anthropogenic environmental impact (Intergovernmental Panel on Climate Change [IPCC], 2014; United Nations Environment Programme [UNEP], 2012). In many ways, the environmental social sciences have been developed through the findings, debates, and contentions that

1 Corresponding author: patrick.t.greiner@vanderbilt.edu. 
surround the relationship between year-to-year changes in social, economic, and political factors, and such impacts - and are meant to examine whether such trends do indeed exist. The nuances of the relationship between carbon dioxide $\left(\mathrm{CO}_{2}\right)$ emissions and a host of other social indicators, such as economic growth, population structures, and technological change, has been the motivating force behind many theoretical and methodological innovations, though such developments have often taken place with the aim of refuting or qualifying the validity of preceding contributions to method or theory. For example, in the field of structural human ecology (SHE), York et al. (2003a) employed cross-national STIRPAT (stochastic impacts by regression on population affluence and technology) analyses to demonstrate the presence of a significant and positive association between economic growth and increases in a nation's environmental footprint. Such findings were built upon and complicated by Liddle (2014) whose work demonstrated the importance of accounting for the demographic age structure of populations in such studies. These contributions continue to be built upon further still, as is well exemplified by recent work that incorporated spatial regression analysis into the traditional STIRPAT formulation in order to illustrate the need to conceptualize the effect of urbanization as a phenomenon that brings about environmental impact in both technological (e.g., spatial) and demographic capacities (McGee et al., 2015).

Interestingly, while the question of how the relationship between human-induced $\mathrm{CO}_{2}$ emissions and social factors-such as those mentioned above-might vary over time has been central to many of the theoretical debates and developments within the diverse field that constitutes the environmental social sciences, few studies to date have chosen to deal with the effect that the passage of time (and more particularly the changes in cultural, technological, and political/institutional factors that are captured by the passage of time) has on the relationship between environmental impact and human activities directly (Jorgenson, 2014; Jorgenson \& Clark, 2012; Jorgenson \& Givens, 2015). Those studies which have dealt with time have, thus far, done so by interacting year dummies with a variable of interest, such as gross domestic product per capita (Jorgenson \& Clark, 2012). Such an approach offers the benefit of allowing researchers to explore how the relationship between two variables, itself, varies from year to year, but it does not allow for the direct exploration of the relationship between time and emissions. Here, I hope to contribute to the field by using a method that, to my knowledge, is novel within the field of SHE to address the effect of factors captured by year-to-year changes in time, such as technological change, on per capita $\mathrm{CO}_{2}$ emissions, while also accounting for the modifying effect that geopolitical context has on this relationship.

In order to effectively explore the role that temporal developments play in the achievement of a greater or lesser degree of emissions, I use a hierarchical linear growth curve modeling approach to better understand how the passage of a year of time affects $\mathrm{CO}_{2}$ emissions per capita on average, while also controlling for the effect 
that a host of other theoretically relevant factors have on this important outcome. The use of the hierarchical linear growth curve modeling approach allows for the investigation of the relationship between time and $\mathrm{CO}_{2}$ emissions per capita, while also allowing other theoretically relevant and empirically measurable factors to be controlled for. The hierarchical structure of the growth curve model also has the benefit of allowing for contemporaneous and extemporaneous factors to be controlled for, making the logic of the hierarchical linear growth curve model similar to that of fixed-effects modeling approaches with fixed-effects estimators for both time and nation-state. However, by using a hierarchical modeling approach, I am also able to control for historical factors, something that presents methodological difficulties in the more traditional fixed-effects modeling approach. Considering the findings of research performed in the unequal ecological exchange and environmental worldsystems literatures (Bunker, 1984; Grimes \& Kentor, 2003; Jorgenson, 2006; Roberts \& Grimes, 1997; Roberts et al., 2003; York et al., 2003b), I account for the effect of historical relations of power over trade networks on the relationship between emissions and temporally variant factors by interacting the temporal variable with the world-systems position (WSP) strata of core, periphery, and semiperiphery. Doing so allows for the development of a more robust understanding of how this relationship varies within the developmental strictures typically placed upon nations belonging to such categories as a result of the contemporary structure of the geopolitical field.

I contextualize the findings of the present research by drawing upon several theoretical traditions within environmental sociology. Specifically, key theories used to understand study findings and to orient the research project are "treadmill of production" (ToP), structural human ecology (SHE), environmental world-systems, and ecological modernization (EM) frameworks. Building upon such scholarship, I employ the methods used here to add greater nuance to the tensions between neo-Marxian understandings of environmental crises and EM perspectives. In doing so, I note that, in many ways, this debate acts as a proxy for the larger debate among policy-makers, activists, and academic experts surrounding the ability of technological progress and potentially growing ecological rationalization to mitigate anthropogenic environmental impact on its own (e.g., absent meaningful structural and policy reform).

\section{Literature review}

While scientific knowledge concerning the potentially devastating effects of climate change - and key anthropogenic drivers behind such changes — has grown immensely, several assumptions that are foundational to modernization hypotheses still seem to limit the incorporation of such knowledge into global mitigation strategies in a number of ways. The influence of the modernization school in 
this respect is perhaps most readily visible in international policy organizations' emphasis on elaborating mitigation strategies that reduce environmental impact while still maximizing economic growth, despite the fact that economic activity is recognized as a key contributor to climate change by the very same institutions (IPCC, 2014). Such strategies reflect an approach to achieving sustainability that still understands and measures international development in terms of various stages of growth (Rostow, 1959), and that seems to suppose that the most appropriate and effective route to sustainability is likely through the introduction of a technical and consumption-based solution that will "consistently produce such a countervailing effect that [it] neutralizes scale effects" (Rosa \& Dietz, 2012, p. 4) of growth in economic activity and population size.

Importantly, the inability to conceptualize a route to global sustainability that incorporates economic stability, as opposed to economic growth, has led to an adoption of mitigation strategies that primarily rely on the ecological rationalization outlined by EM theorists, such as improvements in technological efficiency, the establishment of environmentally conscious political regimes and policies, and a turn toward more environmentally friendly consumption and production patterns (Longo et al., 2016; Sonnenfeld, 2000; York \& Rosa, 2003; Mol, 2010). Considering this, it is of the utmost importance that environmental social science research contribute to the development of a more robust understanding of the effectiveness of modernization strategies with respect to reducing environmental impact. To a large extent, much of macro-structural environmental sociology research has been performed with this goal in mind-a point to which I now turn.

EM theorists developed the EM framework in the last decade of the 20th century in order to provide a counterpoint to the neo-Marxian approaches to environmental sociology that understand environmental crises as an inevitable outcome of modernization processes under capitalism. To that end, EM has focused on developing an understanding of emergent processes of institutional environmental reform (Mol et al., 2014). In particular, EM proponents have focused much of their attention on demonstrating that as socioeconomic processes and institutions develop, or modernize, renewed and intensified environmental concerns and improved efficiency and technology can lead to the decoupling of the economy and environmental impact (Mol, 1997; York \& Rosa 2003; York et al., 2010). Thus, given sufficient time and economic growth, the introduction of environmentally protective political policies, and popular social movements, as well as more environmentally aware choices among consumers-and subsequently producerswithin the marketplace should lead to a relative dematerialization of economic processes and allow for economic growth and environmental mitigation to be compatible (Jorgenson \& Clark, 2012; Mol, 2002; Spaargaren \& Cohen, 2009). 
The process of "ecological rationalization" has been the centerpoint of EM research, which has often relied upon case studies of ecologically reflexive institutions to demonstrate that, even if EM has not spread through our cultural and economic systems wholesale, there are still instances that illustrate the potential, and presence, of such a transition (Mol \& Spaargaren, 2000; Mol et al., 2014; York et al., 2010). Or, as Mol et al. note, "structural human ecology/neo-Malthusian perspectives diverge significantly from ecological modernization theory in that the former are highly abstract, rather than richly particular" (Mol et al., 2014, p. 25). Following the logic of modernization theory, EM proposes that the process of ecological rationalization is fundamental to development, and that, though more developed nations will experience such a rationalization first, all nations will ecologically rationalize as a consequence of the economic growth they may experience, as well as through gaining access to global flows of environmental information and goods (Jorgenson \& Clark, 2012; Mol, 2010; Spaargaren \& Mol, 2008). A central assumption of this approach is that, on the whole, progress under modernization is linear and fairly continuous and will lead to reductions in environmental impact (York, 2004). Yet, despite the centrality of time to the assumption of progress, EM research does not generally deal with, or account for, the potential effects of technological, cultural, or institutional factors associated with time on improvements in ecological outcomes empirically.

Neo-Marxian and SHE perspectives have taken opposing theoretical and methodological approaches to EM in understanding the capacity of institutions and policy-makers to address the environmental crisis through the modernity processes of capitalism. For example, ToP, which was developed by Schnaiberg (1980) to facilitate an understanding of the uptick in pollution and resource extraction following World War II, posits that, due to the Iron Laws of Competition (Marx, 1976), economic processes under capitalism, which also entail economic expansion, will lead to ever-increasing rates of environmental impact. Specifically, theorists in this perspective argue that as more capital is made available to be invested into newer and more efficient technologies, production processes become more and more dependent on these technologies, and capital eventually uses them to replace significant portions of the workforce. The replacement of human labor with new technologies in leading firms has two effects, according to this perspective. First, as new technologies penetrate deeper into the production processes of society, expanded extraction of natural resources would be required in order to provide these new machines with the materials they require to operate properly. The second effect of the growing use of new technology would be that political elites, under pressure from industry to support expansion of production, and from workers to provide a growing job market, enact policies that enable businesses to easily expand into new markets and increase firms' access to natural resources. This expansion, in turn, grows consumption levels, and, as a result, the market for new technologies steadily increases. The end result is a cycle, or "treadmill," that requires ever-greater 
quantities of ecological resources, and produces ever-greater quantities of polluting by-products (Gould et al., 2004; Schnaiberg, 1980; Schnaiberg \& Gould, 2000). In a fashion similar to EM approaches, ToP has temporal processes at the center of its most foundational hypothesis. However, contrary to EM theories, ToP would suggest that with the passage of time there would be ever-greater rates of financial accumulation and industrial expansion, which would result in more pressure being placed on environmental sinks and resources and, thus, ever-greater environmental impacts. Critics of such theories often point to their apparent economic and technological determinism as weaknesses, arguing that they leave no space for the possibility of reform and rationalization that EM examines (Mol et al., 2014).

In addition to differing from the EM perspective in how it conceptualizes the role of temporality in socioecological processes, neo-Marxian approaches such as ToP understand the role that global power relations play in conditioning such processes in a manner that directly challenges the logic of the modernization theory that EM builds upon. Importantly, EM theorists have taken great care to address concerns of eurocentrism within the framework (Mol et al., 2014). Thus, a greater number of EM studies have begun looking at processes of environmental reform, including the presence of environmental Kuznets curves (EKC), in countries throughout the global North (Roach, 2013; Shahbaz et al., 2013), Asia (Baek \& Kim, 2014), and several other nations throughout the global South (Ahmed \& Long, 2013; Chandran \& Tang, 2013; Tiwari et al., 2013). Other critiques of EM have claimed that the perspective ignores the global context of many economic and environmental processes, and have resulted in the development of a new international understanding of EM, which is well represented by the environmental flows approach Mol and others have developed (Mol \& Spaargaren, 2005). However, while EM proponents relying on this approach often posit that global flows of resources, technology, and information will likely lead to a reduction of impacts from social and economic processes across all nations, theorists in environmental world-systems and unequal ecological exchange who draw from, and contribute to, ToP and other neo-Marxian traditions argue instead that global power dynamics, which enable the domination of trade networks and conditions by a few countries, result in less powerful nations being forced into a position where they bear the brunt of the international community's environmental burden (Ergas \& York, 2012; Grimes \& Kentor, 2003; Jorgenson, 2006; Jorgenson \& Clark, 2012; Prell \& Sun, 2015; Roberts \& Grimes, 1997; Roberts et al., 2003; York et al., 2003a; York \& Ergas, 2011). As a result of such a power dynamic, a number of neo-Marxian theorists argue, even if economic growth were to proceed in all nations, many nations would continue to pollute because, in such countries, economic growth is dependent on the establishment and expansion of environmentally intensive economic activities. 
As has been noted above, the field of SHE has been deeply involved in the question of how human activities-including the introduction of new technologies, political policies, and cultural changes - impact the environment. One of the most influential strains of scholarship to deal with such questions in this tradition has been STIRPAT. Contemporary STIRPAT literature, and the SHE methodologies and analyses that draw from it, traces its origins to the IPAT (Impacts = population $\mathrm{x}$ affluence $x$ technology) formulation (Commoner, 1972; Ehrlich \& Holdren, 1972). The development of IPAT - which at its heart is an accounting equation whereby one can determine the value of any particular term so long as the other three are known - centered to a significant degree around debates over the role of technology in how humans impact their environment. Particularly, IPAT developed through a debate between Barry Commoner, who argued that environmental degradation was most appropriately attributed to changes in technology and economic growth (Commoner, 1971), and Paul Ehrlich and John Holdren, who believed that environmental harm was primarily driven by unrestrained population growth (Ehrlich \& Holdren, 1971). For Dietz and Rosa $(1994,1997)$ the debate between Commoner and Ehrlich and Holdren highlighted that, due to its multiplicative nature, IPAT could not be used in order to identify singular causes of anthropogenic impact or to test hypotheses concerned with such matters (Dietz, 2013; Jorgenson, 2013). These realizations led to the elaboration of the IPAT equation into STIRPAT, a tool with which the multiplicative logic of IPAT could be subjected to hypotheses testing in regression analyses. In practice, the difficulty of measuring factors of anthropogenic impact represented by the final $T$ (technology) in the STIRPAT formulation has led to technology being calculated as the exponentiation of the residual in STIRPAT models after accounting for population and affluence (York et al., 2003b). However, a powerful tool in models within, and influenced by, the STRIPAT tradition has been the decomposition of STIRPAT components in order to more closely approximate the effect of technology. As Dietz notes, "it was always clear that unpacking technology would capture a variety of structural effects that vary across contexts" (Dietz, 2013, p. 199), a fact which is well represented by the development of literatures that find their methodological impetus in the STIRPAT tradition.

Despite the importance of the behavior of measures of pollution and sustainability over time to our understanding of the relationship between human activity and environmental impact, and what can be assumed to be a relatively strong relationship between time and changes in factors intended to be captured by the final $T$ of models influenced by STIRPAT, few works in this area have considered the relationship between time and impact in an immediate manner (Jorgenson \& Clark, 2012; Jorgenson, 2014; Jorgenson \& Givens, 2015). To this end, Jorgenson and Clark (2012) examined the effect of economic growth on $\mathrm{CO}_{2}$ emissions conditioned by time by interacting GDP per capita with time in five-year increments. They also take global power relations into account by performing the analyses within 
the context of less developed and highly developed countries. While their findings indicated a minor decoupling of economic growth and $\mathrm{CO}_{2}$ emissions per capita in highly developed countries, no such trend was found in less developed countries. These findings lend support to the notion that more powerful nations reduce their environmental impact by exporting environmentally harmful activities to less powerful countries, or the "pollution-haven" hypothesis (Pearson, 1987). Jorgenson (2014) then built upon the previous work by examining the relationship between the carbon intensity of wellbeing (CIWB) and GDP per capita conditional upon time period. Here, time was again integrated into the study by interacting every fifth year with GDP per capita in five different continents, and findings demonstrated that in all continents except Africa economic development increased CIWB. Recently, this work has been furthered still, as researchers have performed a similar analysis on consumption-based CIWB by interacting GDP per capita and time for every year from 1990 to 2008 in the context of both OECD and non-OECD nations (Jorgenson \& Givens, 2015). Jorgenson and Givens (2015) suggest that economic growth was associated with declines in sustainability across all countries, with the effect being particularly notable in OECD nations_-once again demonstrating that the relationship between economic development and impact must be understood in both a temporal and geopolitical context.

The present study attempts to contribute to this tradition by directly examining the effect of difficult-to-measure factors that change through time on the $\mathrm{CO}_{2}$ emissions per capita, while also accounting for the position nations hold in the world-system, using a hierarchical linear growth curve modeling approach. In performing such an analysis, the present study makes two important contributions to the literature. First, I argue that by examining the association between time and $\mathrm{CO}_{2}$ per capitawhile also accounting for power, age structure, economic development, levels of urbanization, geographic advantage, and contemporaneous factors-one is able to gain insight into the effect of difficult-to-measure variables that are also associated with time, such as ecological awareness of a population, policy changes, and technological improvements that might affect how social processes relate to environmental impact. Using such a technique allows us to approach the issue of time in the context of sustainable development in a new way, and enables us to think about the debate over the role of technology in environmental mitigation from a different angle. Second, here I argue that, though interacting years with economic activity is a good way to understand how particular years modify the effect that growth has on impact, treating time as a continuous variable allows for the development of a more general understanding of how $\mathrm{CO}_{2}$ per capita has been impacted by those factors most directly captured by changes in time when all other theoretically relevant drivers of impact are accounted for. In this way, this research grants us insight into how the combined factors of technological change, environmental policy reform, and the development of ecological concern among consumers and producers affect $\mathrm{CO}_{2}$ emissions per capita in the core, semiperiphery, and periphery of the world-system. 


\section{Data and methods}

With the exception of world-system position (WSP), all variables were drawn from the World Bank (2013) for the years 1960 to 2011. The dependent variable, $\mathrm{CO}_{2}$ emissions per capita, measures $\mathrm{CO}_{2}$ emissions from liquid, gas, and solid fuel consumption in energy production, emissions from main producers of electricity and heat-and emissions from unallocated auto-producers-in million metric tons, divided by the total population within a given nation at a given time.

The independent variable of interest in the present study is time, which is a continuous variable measured in years from 1960 to 2011 . Here, I follow previous work in the SHE tradition, and attempt to capture the effect of technology, which is traditionally viewed as being captured in the residual term of models by disaggregating a model component that encompasses many other relevant factors (Dietz, 2013; Jorgenson, 2013; McGee et al., 2015). However, while many researchers have attempted to capture the impact of technology by disaggregating variables that are known to be fundamental drivers of environmental impact—such as population (Liddle, 2014; Roberts, 2011), or affluence (Shi, 2003; Wang et al., 2013)—here I follow McGee et al. (2015) and attempt to capture technology by bringing a new component into such analyses. Yet, the present study also differs significantly from McGee et al. (2015) in that, where they attempt to capture technology by incorporating a measure of impervious surface development in a nation, I capture the effect of technology and ecological rationales among populations and policy-makers by disaggregating the temporal variable. Disaggregating the temporal variable, in this instance, is achieved by controlling for as many temporally variant, theoretically relevant, and empirically robust and consistent variables as possible. Thus, I argue that time is of interest because, when all time-varying covariates that are empirically robust, and theoretically important to understanding the relationship between social activity and emissions, are accounted for, time then represents those theoretically relevant drivers of impact which we are unable to measure, such as technological progressincluding those technologies associated with the spread and intensification of impervious surfaces, political regime change, and ecological awareness-albeit in an imperfect manner. To that end, the controls included in the models presented below account for a number of factors that are known to have an effect on $\mathrm{CO}_{2}$ emissions per capita and to vary significantly over time, and that are commonly used in macro-quantitative SHE analyses. Importantly, here I do not claim to be accounting for all variables that are theoretically relevant. It is my hope, however, that the inclusion of the independent variables included here can help generate the beginnings of a picture that describes the relationship between the various aspects of ecological rationalization and environmental impact. Specifically, here a nonmonotonic urbanization, the age structure of the population, and a non-monotonic GDP per capita are included in the models in order to control for factors relevant to $\mathrm{CO}_{2}$ emissions per capita that are easily measurable and highly time-variant. 
GDP per capita, measured in 2005 US dollars, is used as a control variable to measure the effect of national-level affluence on emissions. Research in the fields of SHE, ToP, ecologically unequal exchange, and world-systems theory have all found economic growth to be a key contributor to environmental impact and anthropogenic $\mathrm{CO}_{2}$ emissions per capita (Dietz \& Jorgenson, 2015; York et al., 2003c). A quadratic term for GDP per capita is also included in order to allow the relationship between this variable and emissions to be expressed non-linearly. In particular, the inclusion of a quadratic term for GDP per capita allows for the direct examination of the claim in many EM and EKC hypotheses that at greater levels of economic development the impact of economic processes will begin to be alleviated, and even reversed, for a variety of reasons.

Urbanization, or the proportion of the total population living in urban areas, and the ratio of working-age population are included as a control variables in order to account for the ways in which differing demographic structures can drive impacts. Urbanization can be a driver of environmental impact in multiple dimensions. For example, urbanization is often a driver of concurrent industrialization, and thus $\mathrm{CO}_{2}$ emissions. At the same time, processes of urbanization often require the development of the built environment and are predictors of access to energy sources, and thus energy use. As a result, urbanization can be conceptualized as an aspect of development which drives an increase in energy use and manufacturing (Liddle, 2014). Previous work has suggested the presence of an EKC with respect to urbanization and environmental impact as well (Erhardt-Martinez et al., 2002). Further, more recent work has identified the presence of an EKC in the relationship between urbanization and emissions in developing nations (Martínez-Zarzoso \& Antonello, 2011). In order to control for this possibility in the present study, a quadratic term is included for urbanization. In addition to urbanization, it has been found that the proportion of the population that is of working age is deeply tied to the productive capacity of a nation-state and thus is a significant driver of energy use and emissions (McGee et al., 2017; York \& McGee, 2017).

It should be noted that there are other theoretically relevant and empirically robust variables that are not included here, such as foreign direct investment, or the percent of the GDP that is gained from import and export activity. I omit these variables as a result of the fact that they are most typically used in order to capture aspects of ecologically unequal exchange in the international economy. Though these variables work well to capture the effect of such phenomena on GDP per capita, here I am interested in how qualitative, categorical differences in the position of power that a nation-state holds in the global economy modifies the way that aspects of ecological rationality which vary from year to year affect emissions per capita. As a result of this aim, I measure such effects using WSP dummies. Descriptive statistics of key variables according to WSP can be found in Table 1 . 
Table 1: World-system position descriptive statistics.

\begin{tabular}{|l|r|r|r|r|}
\hline Variable & \multicolumn{1}{c|}{ All nations } & \multicolumn{1}{c|}{ Core } & \multicolumn{1}{c|}{ Semi-periphery } & \multicolumn{1}{c|}{ Periphery } \\
\hline Mean GDP per capita & 11241.67 & 18105.05 & 7507.357 & 3572.61 \\
\hline Maximum GDP per capita & 81947.24 & 67804.55 & 81947.24 & 61662.50 \\
\hline Minimum GDP per capita & 113.8766 & 150.55 & 408.72 & 113.87 \\
\hline $\begin{array}{l}\text { Mean } \mathrm{CO}_{2} \text { per capita } \\
\text { (million metric tons) }\end{array}$ & $1.83 \times 10^{-6}$ & $2.63 \times 10^{-6}$ & $1.73 \times 10^{-6}$ & $7.45 \times 10^{-7}$ \\
\hline $\begin{array}{l}\text { Maximum } \mathrm{CO}_{2} \text { per capita } \\
\text { (million metric tons) }\end{array}$ & $1.97 \times 10^{-5}$ & $1.18 \times 10^{-5}$ & $1.97 \times 10^{-5}$ & $1.1 \times 10^{-5}$ \\
\hline $\begin{array}{l}\text { Minimum CO} \\
\text { (million mer capita }\end{array}$ & $1.28 \times 10^{-10}$ & $3.49 \times 10^{-8}$ & $9.40 \times 10^{-9}$ & $1.28 \times 10^{-10}$ \\
\hline Groups (countries) & 91 & 34 & 18 & 39 \\
\hline
\end{tabular}

Source: Author's summary.

I account for power in geopolitical relations by relying upon the WSP measures created by Clark and Beckfield (2009). In order to test for robustness in findings, alternative analyses to those presented here were performed using the more traditional, Snyder and Kick (1979), WSP indicator. The findings reported below were robust across both measures of power. There are 91 nations for which information on environmental indicators and WSP are available that are included in the present study. As a result, I limit my analyses to those 91 nation-states.

Though I use both Snyder and Kick's (1979) and Clark and Beckfield's (2009) measures of WSP in this study, I focus my analysis on those models using Clark and Beckfield's measure because it provides a greater level of parsimony. Specifically, while both measures of WSP are created using network block modeling techniques, the Snyder and Kick (1979) measure performs its block calculations using an index variable that consists of trade flows, treaty participation, occurrence of military intervention, and the presence of diplomatic relations. The Clark and Beckfield (2009) measure only relies on trade network centrality. The result of this is that, though the Snyder and Kick measure acts as an effective gauge of placement in the world-system, the Clark and Beckfield measure is a more easily interpretable measure of power for the purposes of the present study.

Importantly, the models used in this study assume that WSP is relatively fixed in the 51-year period being examined. While the degree of mobility of nations within the world-system is an unsettled issue, there is a precedent of treating the position of nations as fixed over periods of time that may be considered brief relative to the 550-year time span within which the modern world-system has developed (Clark \& Beckfield, 2009; Snyder \& Kick, 1979). Understanding this, I contend that the position of power held by a nation in the international economy during the early years of the postwar era was one of many key factors that contributed to the adoption of political, social, and economic policy programs that were determinative 
with regards to the ways the nation interacted with the environment over the period of time observed in this study. In order to test this assumption, an alternative model was explored where WSP was enabled to be slightly dynamic following the year 1989. The year 1989 was chosen in order to capture potential changes to WSP that occurred during and after the collapse of the Soviet Union. To capture such change, following 1989 WSP was coded according to Clark's (2012) updated, post-Cold War era, WSP indicator. Findings did not differ substantially from those presented below, and, as a result, I focus on the more parsimonious (fixed WSP) model. A list of WSP nations in this study can be found in Table 2 .

Table 2: World-system position measure nation classifications.

\begin{tabular}{|l|l|l|}
\hline Core & Semi-periphery & Periphery \\
\hline Argentina, Australia, Austria, & Chile, Colombia, Cote d'Ivoire, & Benin, Bolivia, Cambodia, \\
Belgium, Brazil, Bulgaria, & Cyprus, Iraq, Israel, Kenya, & Cameroon, Congo (Dem. Rep.), \\
Canada, China, Czech & Kuwait, Libya, Nigeria, Panama, & Congo (Rep.), Costa Rica, \\
Republic, Denmark, Finland, & Peru, Philippines, Sri Lanka, & Cuba, Dominican Republic, \\
France, Germany, Greece, & Tunisia, United Arab Emirates, & Ecuador, El Salvador, Ethiopia, \\
Hungary, India, Iran, Ireland, & Uruguay, Venezuela & Gabon, Ghana, Guatemala, \\
Italy, Japan, South Korea, & & Haiti, Honduras, Iceland, \\
Malaysia, Mexico, Morocco, & & Jamaica, Jordan, Lebanon, \\
Netherlands, New Zealand, & & Malta, Mongolia, Nepal, \\
Norway, Pakistan, Poland, & & Nicaragua, Paraguay, Senegal, \\
Portugal, Russian Federation, & & South Africa, Sudan, Syrian \\
Saudi Arabia, Spain, Sweden, & & Arab Republic, Togo, Trinidad \\
Switzerland, Thailand, Turkey, & & and Tobago, Vietnam, Yemen \\
United Kingdom, United States & & \\
\hline
\end{tabular}

Source: Clark and Beckfield (2009).

With the exception of WSP and time, all variables in the study were natural log transformed, making the such variables presented in the models below elasticities. The result of this is that all coefficients below represent the percent change in $\mathrm{CO}_{2}$ per capita associated with a 1-unit change in the independent variable (York et al., 2003b).

I use a hierarchical linear growth curve model, with years nested within nations, to perform the analyses presented below. Such an approach is beneficial, as hierarchical linear models entail a precise weighting operation that prevent the biasing of coefficients or standard errors by unusual observations or panel sizes. Additionally, the clustering of years within nations serves to control for both contemporaneous and extemporaneous effects. Controlling for these two factors serves to limit the influence of omitted variable bias substantially. Further accounting for contemporaneous factors, or the clustering of years, allows for the effect of changes from one year to another, such as changes in technology, culture, policies, and institutions to be captured within the time variable. Thus, the effect of a one-year 
change in time corresponds to the average effect of within-nation changes of such factors. The general structure of the hierarchical linear growth curve model used here is as follows:

$$
\begin{gathered}
C O_{2} P C_{i t}=\beta_{0 i}+\beta_{1}\left(\text { GDPPC }_{i t}\right)+\beta_{2}\left(\text { GDPPC }_{i t}^{2}\right)+\beta_{3}\left(\text { Urban }_{i t}\right)+\beta_{4}\left(\text { Urban }_{i t}^{2}\right) \\
+\beta_{5}\left(\text { Productive Age }_{i t}\right)+\beta_{6 i}\left(\text { time }_{i t}\right)+e_{\text {oit }} \\
\beta_{0 i}=\beta_{0}+\beta_{7}\left(\text { Core }_{i}\right)+\beta_{8}\left(\text { Semi }_{i}\right)+\beta_{9}\left(\text { Peri }_{i}\right)+\mu_{0 i} \\
\beta_{6 i}=\beta_{0}+\beta_{10}\left(\text { Core }_{i}\right)+\beta_{11}\left(\text { Semi }_{i}\right)+\beta_{12}\left(\text { Peri }_{i}\right)+\mu_{1 i}
\end{gathered}
$$

Level 2: $\left[\begin{array}{c}\mu o i \\ \mu 1 i\end{array}\right] \sim \mathrm{N}\left(0,\left[\begin{array}{ll}\sigma_{u 0}^{2} & \\ & \sigma_{u 1}^{2}\end{array}\right]\right.$

Level 1: $e_{0 \mathrm{it}}-\mathrm{N}\left(0, \sigma_{\mathrm{e} 0}^{2}\right)$

Where $\mathrm{CO}_{2} \mathrm{PC}_{i t}$ represents the log of per capita $\mathrm{CO}_{2}$ emissions of the $i$ th nation in year $t$; GDPPC $_{i t}$ is the logged value of nation $i$ ' GDP per capita in time period $t$; $G D P P C_{i t}^{2}$ is the $\log$ of the quadratic term for country $i$ in year $t$; urban $n_{i t}$ is the $\log$ of the percent of the population living in urban areas in nation $i$ during year $t$. Urban ${ }_{i t}^{2}$ is the quadratic term for the log of urban population percentage; time $_{i t}$ is the value of the variable time in country $i$ during year $t ;$ Peri $_{i}$ is the binary measurement of the periphery status of nation $i$; Semi $i_{i}$ is the binary measurement of the semi-periphery status of nation $i$; Core $e_{i}$ is the binary measurement of the core status of nation $i ; \mathrm{e}_{0 i t}$ is the residual difference in $\mathrm{CO}_{2}$ emissions per capita for the $i$ th country in year $t$; $\mu_{0 i}$ is the residual differential $\mathrm{CO}_{2}$ emissions per capita value for country $i$ when all predictor variables are held at $0 ; \mu_{1 i}$ is the residual difference in $\mathrm{CO}_{2}$ emissions per capita change for nation $i$ for every additional 1 -unit increase in time. $\sigma_{u 0}^{2}$ represents the between-nation variance in $\mathrm{CO}_{2}$ emissions per capita; $\sigma_{u 1}^{2}$ is the between-nation variance in $\mathrm{CO}_{2}$ emissions per capita change for every 1-unit increase in time.

\section{Results and discussion}

The results of the hierarchical linear growth curve model analyses are presented in Table 3 below. Model A demonstrates the effect of time on $\mathrm{CO}_{2}$ emissions per capita absent of any theoretically relevant time-variant controls. The results indicate that every year of temporal change, on average, results in a $0.025 \%$ increase in $\mathrm{CO}_{2}$ emissions per capita. 
Table 3: Hierarchical linear growth curve model of the effect of time on $\mathrm{CO}_{2}$ emissions per capita.

\begin{tabular}{|c|c|c|c|}
\hline Variable & Model A & Model B & Model C \\
\hline \multicolumn{4}{|l|}{ Level 1 variables } \\
\hline GDP per capita & - & $\begin{array}{r}2.346^{\star \star \star} \\
(0.176) \\
\end{array}$ & $\begin{array}{r}2.539^{\star \star \star} \\
(0.178) \\
\end{array}$ \\
\hline GDP per capita2 & - & $\begin{array}{r}-0.091^{\star \star \star} \\
(0.010) \\
\end{array}$ & $\begin{array}{r}-0.112^{\star \star \star} \\
(0.011) \\
\end{array}$ \\
\hline Urbanization & - & $\begin{array}{r}-5.572^{\star \star \star} \\
(0.370) \\
\end{array}$ & $\begin{array}{r}-5.331^{\star \star \star} \\
(0.365) \\
\end{array}$ \\
\hline Urbanization2 & - & $\begin{array}{r}0.901^{\star \star \star} \\
(0.053) \\
\end{array}$ & $\begin{array}{r}0.890^{\star \star \star *} \\
(0.052) \\
\end{array}$ \\
\hline Ratio of working age population & - & $\begin{array}{l}-0.012 \\
(0.047) \\
\end{array}$ & $\begin{array}{l}-0.019 \\
(0.046) \\
\end{array}$ \\
\hline Time & $\begin{array}{r}0.025^{\star \star \star} \\
(0.001) \\
\end{array}$ & $\begin{array}{r}0.002 \\
(0.001) \\
\end{array}$ & $\begin{array}{r}0.011^{\star \star \star} \\
(0.002) \\
\end{array}$ \\
\hline \multicolumn{4}{|l|}{ Level 2 variables } \\
\hline Periphery & - & - & $\begin{array}{r}30.676^{\text {** }} \\
(3.340) \\
\end{array}$ \\
\hline Semi-periphery & - & - & $\begin{array}{r}16.848^{\star \star \star} \\
(3.881) \\
\end{array}$ \\
\hline Core (reference) & - & - & - \\
\hline \multicolumn{4}{|l|}{ Cross-level interactions } \\
\hline Year $\mathrm{x}$ periphery & - & - & $\begin{array}{r}-0.0158^{\star \star \star} \\
(0.002) \\
\end{array}$ \\
\hline Year $x$ semi-periphery & - & - & $\begin{array}{r}-0.009^{\star \star \star} \\
(0.002) \\
\end{array}$ \\
\hline Year $x$ core (reference) & - & - & - \\
\hline Constant & -50.873 & -10.346 & -27.347 \\
\hline \multicolumn{4}{|l|}{ Variance terms } \\
\hline$\sigma_{e o}^{2}$ (Year level) & 0.293 & 0.225 & 0.219 \\
\hline$\sigma_{u 0}^{2}$ (Country level) & 4.393 & 1.606 & 0.278 \\
\hline$\sigma_{u 1}^{2}$ & - & - & $3.03 e-7$ \\
\hline
\end{tabular}

Notes: All models include 91 nations and 3,556 nation-years. ${ }^{* \star \star} \mathrm{p}<0.001$; standard errors in parentheses. Source: Author's summary of model.

Model $\mathrm{B}$ examines the effect that time has on $\mathrm{CO}_{2}$ emissions per capita while holding constant theoretically relevant variables, without taking global power structure into consideration. Findings suggest that, outside the effect of changes in population, economic development, and urbanization — which are controlled for in both Model $\mathrm{B}$ and Model C-time has no effect on $\mathrm{CO}_{2}$ emissions per capita when context is not considered. 
Model C controls for all theoretically relevant time-variant variables and also examines variation in the effect of time in nations belonging the core, semiperiphery, and periphery. Findings suggest that in the core, a one-year increase in the temporal variable is associated with an increase of $0.01 \%$ in $\mathrm{CO}_{2}$ emissions per capita. The effect of time-variant factors on $\mathrm{CO}_{2}$ emissions decreases by $0.009 \%$ in semi-periphery nations, resulting in an increase of $0.001 \%$ in kilograms of $\mathrm{CO}_{2}$ emissions per capita being associated with a change of one year. Interestingly, periphery nations are found to have an even greater decrease in the effect that time has on $\mathrm{CO}_{2}$ emissions per capita, 0.0159 , suggesting that in such nations the passage of a year of time is associated with a slight decrease of $0.0059 \%$ in $\mathrm{CO}_{2}$ emissions per capita on average. The graphic representation of these relationships can be seen in Figure 1. With the exception of the working age ratio variable, all regression coefficients reported in Model C were found to be statistically significant at the 0.001 alpha level with a two-tailed test. Considering the importance of questions around the impact that economic growth has on environment health, it is important to note that Model $\mathrm{C}$ indicates that there is an attenuation in the relationship between GDP per capita and $\mathrm{CO}_{2}$ emissions per capita, such that as GDP per capita reaches very high levels its effect on emissions decreases substantially. Importantly, this research does not examine if, or how, this relationship is modified by power differentials in the global economy, which is an important consideration in such discussions. Additionally, I note that the relationship between GDP per capita and emissions remains positive throughout the range of observed values. Thus, the model indicates that even when nations achieve what might be seen as unusually high levels of GDP per capita ( $\$ 81,947.24$ in 2005 US dollars), economic growth is still found to result in increases in emissions. Likelihood ratio tests between Models B and $\mathrm{C}$ suggest that Model $\mathrm{C}$ provides the best fit to the data: as a result of this, I focus the discussion on this model.

Overall, the findings presented here suggest that factors captured by the passage of time that, as of yet, are not able to be directly measured and controlled for on the international scale-such as technological change, changes in policy approaches and political regimes at the national and international level, changes in the level of ecological concern among producers and consumers, and other aspects of ecological rationalization-do have a significant effect on $\mathrm{CO}_{2}$ emissions per capita. While the association of time and $\mathrm{CO}_{2}$ is modest in all world-systems categories, it is also found to be highly significant, and, importantly, significantly different in every world-system strata. 


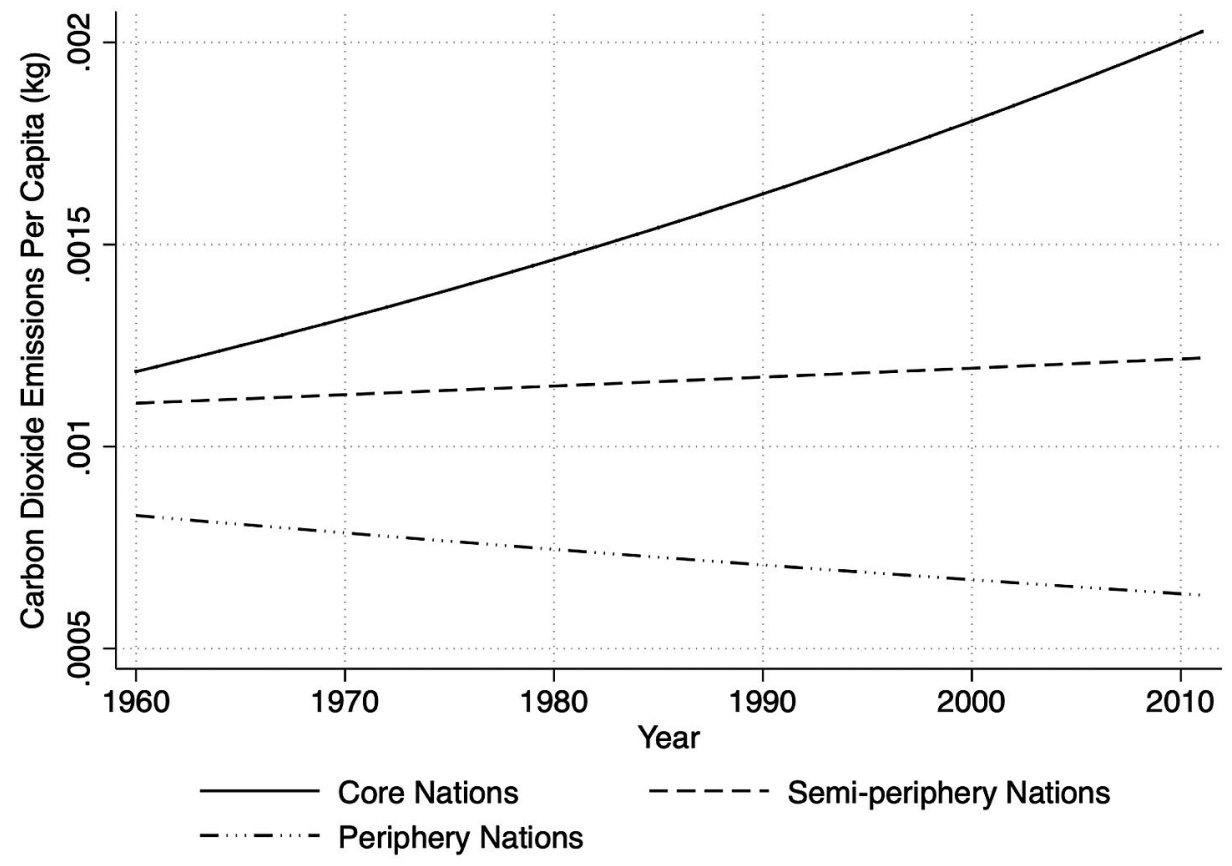

Figure 1: Estimated effects of time-variant factors on $\mathrm{CO}_{2}$ emissions per capita.

Source: Author's summary of model findings.

The findings of the present research complicate our understanding of the role that social factors that change over time have on $\mathrm{CO}_{2}$ emissions in interesting ways. For example, the fact that all three world-systems categories have relationships that are significantly different from one another provides support for the supposition of environmental world-systems scholars that, due to the nature of power relations in the international economy, nations holding different positions in the world-system will have notably different social and economic structures which will ultimately lead to notable differences in the impact that such nations' socioeconomic activities have on the environment. Thus, as Figure 1 demonstrates, time is associated with increases in $\mathrm{CO}_{2}$ emissions per capita to a greater degree in core nations than it is in the semi-periphery, and is associated with decreases in $\mathrm{CO}_{2}$ emissions per capita in the periphery. However, the specific relationship between time-variant factors of interest and $\mathrm{CO}_{2}$ emissions per capita do not necessarily support a world-systems understanding of how such a relationship should play out in each world-system category. For example, if this relationship is viewed strictly through the environmental world-systems lens, then it might be considered surprising that all nations in the analysis except for those belonging to the periphery express a positive association between time and emissions. In particular, this finding seems to challenge the well-established "pollution-haven" hypothesis (Pearson, 1987), 
where core nations improve socioecological relations by exporting environmentally harmful production processes to nations in the semi-periphery and periphery. Despite this apparent contradiction, if viewed with an eye toward consumption, then these findings do seem to offer support to environmental world-systems hypotheses, which note that labor forces in such nations, "being poorly paid, cannot constitute an important consumer market" (Roberts et al., 2003), and thus cannot account for great increases in consumption of energy. This insight, when taken in conjunction with insights of from the "displacement paradox" and the "Jevon's paradox" - which, respectively, note that new technologies are often used in addition to older technologies, and that increases in technological efficiency often lead to the technology being used by consumers at greater rates (York, 2006; York \& McGee, 2016)—provides a plausible explanation of these initially surprising findings. Considering these theoretical contributions, we should not necessarily be surprised to see factors such as technological change, policy change, and increasing ecological concern associated with increases in emissions in the core, as it is possible that 1) new technologies, particularly in the energy sector, are being used in order to expand markets in the core, rather than replacing older technologies (York, 2012), and 2) increases in efficiency are leading to increases in consumption, as has recently been found to be the case in the United States with alternative fuel vehicles (McGee, 2018).

The existence of a positive relationship between time-variant factors and emissions in the semi-periphery indicates that these nations might be experiencing increases in emissions as a result of taking on environmentally harmful production processes in order to provide consumer goods for nations in the core, thereby increasing the use of energy that is required to sustain manufacturing processes. Thus, this finding offers support for environmental world-systems' "pollution-haven" hypothesis (Pearson, 1987; Roberts et al., 2003).

The negative relationship between the temporal variable and emissions in nations in the periphery offers support to both environmental world-systems theory and to Mol's theory of environmental flows. Specifically, we should expect periphery nations to release fewer production- and consumption-related emissions (Smith \& White, 1992; Roberts et al., 2003; Van Rossem, 1996) than those belonging to the semi-periphery and core due to the fact that such nations often rely on niche economies (such as tourism) or human and non-human animal labor to grow their GDP. Further, as noted above, in many less powerful nations, large shares of the populations are not necessarily economically empowered enough to increase their rates of consumption or access to infrastructures. In spite of this, such nations often still have access to some of the benefits of technological and cultural change that EM, and environmental flows theory in particular, notes is fundamental to ecological rationalization. For example, it is possible that increases in access to 
information technologies in such nations has the effect of raising concern over global environmental issues and leads to effective political mobilization strategies which are aimed at reducing local and national-level environmental impact, though more research should be done to explore the validity of this possibility. Thus, while previous research has suggested that information technologies can, in fact, exacerbate environmental problems (Longo \& York, 2015), perhaps in those nations which exert the least power in the international market that is not the case. It should also be noted that, if environmental flows are responsible for the decline in emissions associated with temporal change in the way described above, then this suggests that the beneficial environmental outcomes we see in the periphery are, in large part, the result of severe global inequalities that the global community should seek to correct. Put differently, we cannot rely on such mechanisms to correct the global environmental crisis, as they are deeply tied to the global environmental inequality that most supra-national and national institutions aim to alleviate.

While these findings offer support to the notion that flows of environmental goods and information will benefit less powerful countries in the global economy, they also challenge the hypothesis of EM that all nations will improve in their relationship to the environment, given enough time, as a result of a global process of ecological rationalization. Rather, the findings presented here suggest that, in the majority of nations, time-dependent factors are associated with increases in $\mathrm{CO}_{2}$ emissions per capita. It is important to note that, as indicated above, the majority of emissions have historically come from nations belonging to the core and the semi-periphery (as can be seen in Table 1), as a result, we should expect that-supposing the trends observed here continue- $-\mathrm{CO}_{2}$ emissions per capita will continue to increase globally. The models presented here focus on changes in per capita emissions, and as a result are subject to being driven by change in the denominator (i.e., change in population). Figure 2 displays the average change in population within each of the world-system categories used in the present study. I note that the general increase in population within each category should lead us to expect a decline in per capita emissions unless total emissions are increasing at a rate that is greater than the rate of increase in population within such nations. These trajectories suggest that the present results are not being driven by a denominator effect. 


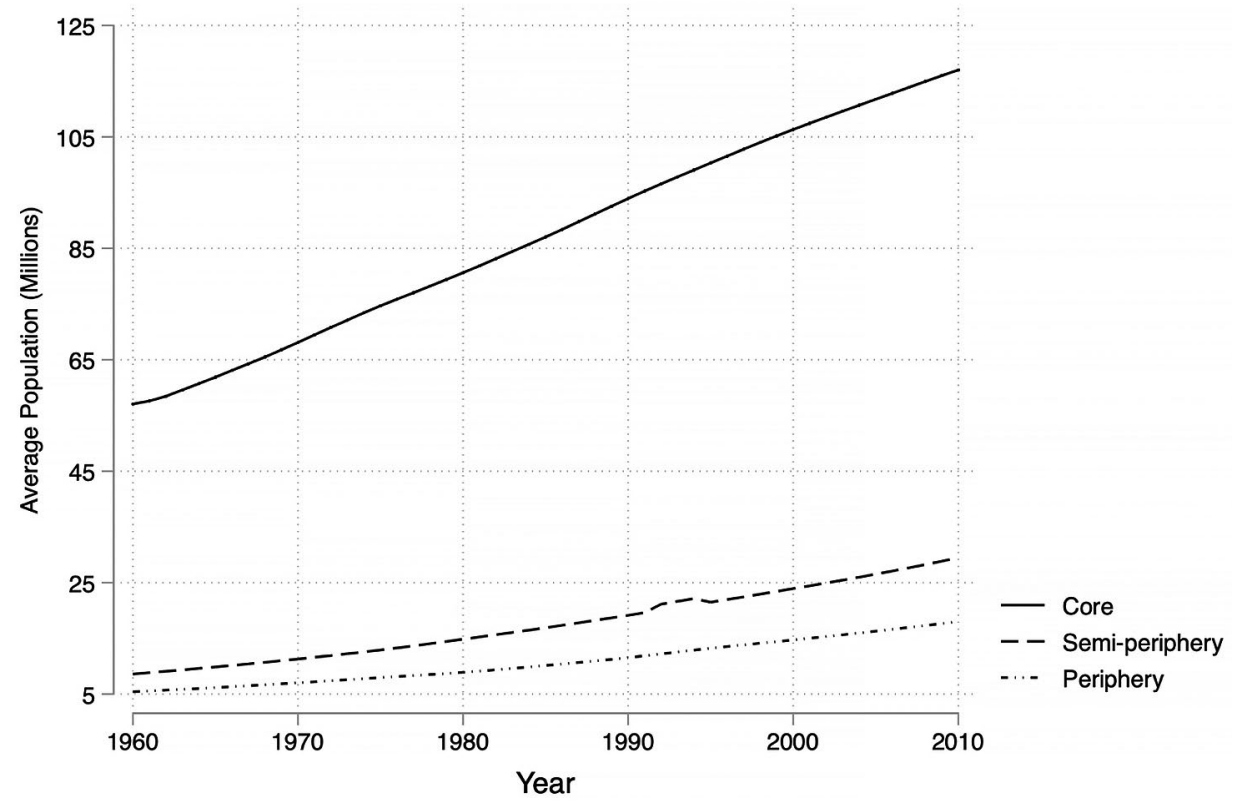

Figure 2: Change in average total population size within world-system strata.

Source: Author's summary of model findings.

\section{Conclusion}

This study draws from SHE, neo-Marxian environmental theory, environmental world-systems theory, and EM literature, and uses a hierarchical linear growth curve modeling approach in order to examine the association between social factors associated with environmental impact that change over time, and $\mathrm{CO}_{2}$ emissions per capita in the world-system. Using such an approach, I examine the debate between EM theorists and environmental world-systems proponents in a novel way. By disaggregating time, and using it as a variable of interest, I gain insight into the contentious issue of the extent to which the aggregate of changes in technological efficiency, policy approaches, and the ecological awareness of producers and consumers, as well as other unmeasured aspects of ecological rationalization, affect emissions at the national level.

Building on work that has found that changes in time modify the relationship between economic activity and emissions, I find that the relationship between time and $\mathrm{CO}_{2}$ emissions per capita is statistically significant, as well as statistically different across world-systems strata. In particular, the findings here suggest that, in all nations except for those belonging to the periphery, time is positively associated with $\mathrm{CO}_{2}$ emissions per capita, with the strongest association being in the core of 
the world-system. This finding suggests that, outside of the periphery, the process of ecological rationalization is likely not working to reduce the rate of emissions over time, and supports the argument of SHE and environmental world-systems scholars that broader structural changes will likely need to be made to the global economy if we hope to reduce the environmental impact of social processes.

In a broader sense, the findings presented in this study suggest that assumptions that temporal progress in technological change, ecological awareness, and environmentally friendly policies and political regimes, and other aspects of ecological rationality, lead to a gradual decline in the environmental impact of social processes are not necessarily valid, at least insofar as greenhouse gas emissions are concerned. What's more, the findings presented here indicate that the modernist assumption of global economic processes leading to increasing similarities in the way that nations relate to the environment is a questionable one, and that, in fact, nations that belong to different world-systems positions_-or have notably different levels of control over their trade network and, thus, their role in the international economy and production chain-have trajectories of growth in $\mathrm{CO}_{2}$ emissions per capita that are decidedly different from one another. The implication of these findings is that international policy-makers must account for such differences as they attempt to outline pathways to sustainability for all nations. Further, the findings presented above suggest that - at both the national and the international level-policy-makers must take a more active role in ensuring that social structures and processes become more environmentally benign, rather than assuming that socioecologically sustainable societies will roll in on the wheels of inevitability. To that end, the findings of this study point in two broad research directions. First, as mentioned above, disaggregating time allows for the rough approximation of the effect of theoretically relevant, temporally variant social factors on emissions and environmental impact. As a result of this fact, and the approximate nature of the analyses, the findings here should be seen as one part of a larger conversation and not a final word. Further, disaggregation of time will become more effective as a greater number of theoretically relevant variables become more readily available and more reliable. With this fact in mind, it is important that continual efforts are made to more precisely track the effect on $\mathrm{CO}_{2}$ emissions per capita of those factors that were captured by time in this study. Second, it is important that comparative and qualitative work be done in order to better understand what causes the relationship between time and $\mathrm{CO}_{2}$ emissions to differ across world-system positions, as well as what interventions might successfully limit these differences. 


\section{References}

Ahmed, K., \& Long, W. (2013). An empirical analysis of CO2 emission in Pakistan using EKC hypothesis. Journal of International Trade, Law and Policy, 12(2), 188-200. doi.org/ 10.1108/jitlp-10-2012-0015.

Baek, J., \& Kim, H. S. (2014). Is economic growth good or bad for the environment? Empirical evidence from Korea. Energy Economics, 36, 744-749. doi.org/10.1016/ j.eneco.2012.11.020.

Bunker, S. G. (1984). Modes of extraction, unequal exchange, and the progressive underdevelopment of an extreme periphery: The Brazilian Amazon, 1600-1980. American Journal of Sociology, 1017-1064. doi.org/10.1086/227983.

Chandran, V. G. R., \& Tang, C. F. (2013). The dynamic links between CO2 emissions, economic growth and coal consumption in China and India. Applied Energy, 104, 310 318. doi.org/10.1086/227983.

Clark, R. (2012). World-system position and democracy, 1972-2008. International Journal of Comparative Sociology, 53(5-6), 367-399.

Clark, R., \& Beckfield, J. (2009). A new trichotomous measure of world-system position using the international trade network. International Journal of Comparative Sociology, 50(1), 5-38. doi.org/10.1177/0020715208098615.

Commoner, B. (1971). The closing circle. New York, NY: Knopf.

Commoner, B. (1972). A Bulletin dialogue on "The closing circle": Response. Bulletin of the Atomic Scientists, 28(5), 17, 42-56.

Dietz, T. (2013). Context matters: Eugene A. Rosa’s lessons for structural human ecology. In T. Dietz \& A. Jorgenson (Eds.), Structural human ecology: New essays in risk, energy and sustainability (pp. 189-215). Pullman, WA: Washington State University Press. doi.org/10.5195/jwsr.2015.24.

Dietz, T., \& Jorgenson, A. (2015). Introduction: Progress in structural human ecology. Human Ecology Review, 22(1), 3-12. doi.org/10.22459/her.22.01.2015.01.

Dietz, T., \& Rosa, E. A. (1997). Effects of population and affluence on CO2 emissions. Proceedings of the National Academy of Sciences, 94(1), 175-179. doi.org/10.1073/pnas. 94.1.175.

Dietz, T., \& Rosa, E. A. (1994). Rethinking the environmental impacts of population, affluence and technology. Human Ecology Review 1(2), 277-300.

Ehrhardt-Martinez, K., Crenshaw, E. M., \& Jenkins, C. (2002). Deforestation and the environmental Kuznets curve: A cross-national investigation of intervening mechanisms. Social Science Quarterly, 83(1), 226-243. doi.org/10.1111/1540-6237.00080.

Ehrlich, P. R., \& Holdren, J. P. (1971). Impact of population growth. Science, 171, 1212-1217. 
Ehrlich, P. R., \& Holdren, J. P. (1972). A Bulletin dialogue on "The closing circle": Critique. One dimensional ecology. Bulletin of the Atomic Scientists, 28(5), 16-27. doi.org/10.1080/ 00963402.1972 .11457930 .

Ergas, C., \& York, R. (2012). Women's status and carbon dioxide emissions: A quantitative cross-national analysis. Social Science Research, 41(4), 965-976. doi.org/10.1016/ j.ssresearch.2012.03.008.

Gould, K. A., Pellow, D. N., \& Schnaiberg, A. (2004). Interrogating the treadmill of production: Everything you wanted to know about the treadmill but were afraid to ask. Organization \& Environment 17(3), 296-316. doi.org/10.1177/1086026604268747.

Grimes, P., \& Kentor, J. (2003). Exporting the greenhouse: Foreign capital penetration and $\mathrm{CO}_{2}$ emissions 1980-1996. Journal of World-Systems Research, 9(2), 261-275. doi.org/ 10.5195/jwsr.2003.244.

Intergovernmental Panel on Climate Change (IPCC). (2014). Fifth assessment report. Geneva, Switzerland: IPCC.

Jorgenson, A. K. (2006). Unequal ecological exchange and environmental degradation: A theoretical proposition and cross-national study of deforestation, 1990-2000. Rural Sociology, 71(4), 685-712. doi.org/10.1526/003601106781262016.

Jorgenson, A. (2013). Population affluence and greenhouse gas emissions: The continuing significance of structural human ecology and the utility of STIRPAT. In T. Dietz \& A. Jorgenson (Eds.), Structural human ecology: New essays in risk, energy and sustainability (pp. 139-157). Pullman, WA: Washington State University Press. doi.org/10.5195/ jwsr.2015.24.

Jorgenson, A. K. (2014). Economic development and the carbon intensity of human wellbeing. Nature Climate Change, 4(3), 186-189. doi.org/10.1038/nclimate2110.

Jorgenson, A. K., \& Clark, B. (2012). Are the economy and the environment decoupling? A comparative international study, 1960-2005. American Journal of Sociology, 118(1), 1-44. doi.org/10.1086/665990.

Jorgenson, A. K., \& Givens, J. (2015). The changing effect of economic development on the consumption-based carbon intensity of well-being, 1990-2008. PLoS One, 10(5), e0123920. doi.org/10.1371/journal.pone.0123920.

Liddle, B. (2014). Impact of population, age structure, and urbanization on carbon emissions/energy consumption: Evidence from macro-level, cross-country analyses. Population and Environment, 35(3), 286-304. doi.org/10.1007/s11111-013-0198-4.

Longo, S., Clark, B., Shriver, T., \& Clausen, R. (2016). Sustainability and environmental sociology: Putting the economy in its place and moving toward an integrative socioecology. Sustainability, 8(5), 437. doi.org/10.3390/su8050437.

Longo, S., \& York, R. (2015). How does information communication technology affect energy use? Human Ecology Review, 22(1), 55-72. doi.org/10.22459/her.22.01.2015.04. 
Martinez-Zarzoso, I., \& Antonello, M. (2011). The impact of urbanization on $\mathrm{CO}_{2}$ emissions: Evidence from developing countries. Ecological Economics, 49(4), 431-455. doi.org/10.1016/j.ecolecon.2011.02.009.

Marx, K. (1976). Capital, Volume I. Harmondsworth, UK: Penguin/New Left Review.

McGee, J. A. (2018). The treadmill of alternatively fueled vehicle production. Human Ecology Review, 23(1), 81-99. doi.org/10.22459/her.23.01.2017.05.

McGee, J. A., Clement, M. T., \& Besek, J. F. (2015). The impacts of technology: A reevaluation of the STIRPAT model. Environmental Sociology, 1(2), 81-91. doi.org/10.10 80/23251042.2014.1002193.

McGee, J. A., Ergas, C., Greiner, P. T., \& Clement, M. T. (2017). How do slums change the relationship between urbanization and the carbon intensity of well-being? PLoS One, 12 . doi.org/10.1371/journal.pone.0189024.

Mol, A. P. J. (1997). Ecological modernization: Industrial transformations and environmental reform. In M. R. Redclift \& G. Woodgate (Eds.), The international handbook of environmental sociology (pp. 138-49). Cheltenham, UK: Edward Elgar Publishing Limited. doi.org/10.4337/9781843768593.00016.

Mol, A. P. J. (2002). Ecological modernization and the global economy. Global Environmental Politics, 2(2), 92-115. doi.org/10.1162/15263800260047844.

Mol, A. P. J. (2010). Ecological modernization as a social theory of environmental reform. In A. Mol, G. Spaargaren, \& D. Sonnenfeld (Eds.), The Ecological Modernisation Reader (pp. 63-76). London: Routledge. doi.org/10.4324/9780203814550.ch2.

Mol, A. P. J., \& Spaargaren, G. (2000). Ecological modernisation theory in debate: a review. Environmental Politics, 9(1), 17-49. doi.org/10.1080/09644010008414511.

Mol, A. P. J., \& Spaargaren, G. (2005). From additions and withdrawals to environmental flows: Reframing debates in the environmental social sciences. Organization \& Environment, 18(1), 91-107. doi.org/10.1177/1086026604270459.

Mol, A. P. J., Spaargaren, G. \& Sonnenfeld, D. A. (2014). Ecological modernization theory: Taking stock, moving forward. In S. Lockie, D. A. Sonnenfeld, \& D. R. Fisher (Eds.), Handbook of social and environmental change (pp. 15-30). New York: Routledge. doi.org/ 10.4324/9780203814550.ch2.

Pearson, C. (1987). Environmental standards, industrial relocation, and pollution havens. In C. Pearson (Ed.), Multinational corporations, the environment, and the third world (pp. 113-128). Durham, NC: Duke University Press.

Prell, C., \& Sun, L. (2015). Unequal carbon exchanges: Understanding pollution embodied in global trade. Environmental Sociology, 1(4), 256-267. doi.org/10.1080/23251042.2015. 1114208. 
Roach, T. (2013). A dynamic state-level analysis of carbon dioxide emissions in the United States. Energy Policy, 59, 931-937. doi.org/10.1016/j.enpol.2013.04.029.

Roberts, J. T., \& Grimes, P. E. (1997). Carbon intensity and economic development 19621991: A brief exploration of the environmental Kuznets curve. World Development, 25(2), 191-198. doi.org/10.1016/S0305-750X(96)00104-0.

Roberts, J. T., Grimes, P. E., \& Manale, J. (2003). Social roots of global environmental change: A world-systems analysis of carbon dioxide emissions. Journal of World-Systems Research, 9(2), 277-315. doi.org/10.5195/jwsr.2003.238.

Roberts, T. D. (2011). Applying the STIRPAT model in a post-Fordist landscape: Can a traditional econometric model work at the local level? Applied Geography, 31, 731-739. doi.org/10.1016/j.apgeog.2010.06.010.

Rosa, E. A., \& Dietz, T. (2012). Human drivers of national greenhouse-gas emissions. Nature Climate Change, 2(8), 581-586. doi.org/10.1038/nclimate1506.

Rostow, W. W. (1959). The stages of economic growth. The Economic History Review, 12(1), $1-16$.

Schnaiberg, A. (1980). Environment: From surplus to scarcity. New York, NY: Oxford University Press.

Schnaiberg, A., \& Gould, K. A. (2000). Environment and society: The enduring conflict. Caldwell, NJ: Blackburn Press.

Shahbaz, M., Mutascu, M., \& Azim, P. (2013). Environmental Kuznets curve in Romania and the role of energy consumption. Renewable and Sustainable Energy Reviews, 18, 165173. doi.org/10.1016/j.rser.2012.10.012.

Shi, A. (2003). The impact of population pressure on global carbon dioxide emissions, 1975-1996: Evidence from pooled cross-country data. Ecological Economics, 44(1), 29-42. doi.org/10.1016/s0921-8009(02)00223-9.

Smith, D. A., \& White, D. R. (1992). Structure and dynamics of the global economy: Network analysis of international trade 1965-1980. Social Forces, 70(4), 857-893. doi.org/10.1093/sf/70.4.857.

Snyder, D., \& Kick, E. L. (1979). Structural position in the world system and economic growth, 1955-1970: A multiple-network analysis of transnational interactions. American Journal of Sociology, 84(5), 1096-1126. doi.org/10.1086/226902.

Sonnenfeld, D. A. (2000). Developing countries: Contradictions of ecological modernisation: Pulp and paper manufacturing in South-east Asia. Environmental Politics, 9(1), 235-256. doi.org/10.1080/09644010008414518. 
Spaargaren, G., \& Cohen, M. J. (2009). Greening lifecycles and lifestyles: Sociotechnical innovations in consumption and production as core concerns of ecological modernisation theory. In P. J. A. Mol, D. A. Sonnenfeld \& G. Spaargaren (Eds.), The ecological modernisation reader: Environmental reform in theory and practice (pp. 257-274). London and New York: Routledge. doi.org/10.1177/0268580911411526.

Spaargaren, G., \& Mol, A. P. J. (2008). Greening global consumption: Redefining politics and authority. Global Environmental Change, 18(3), 350-359. doi.org/10.1016/ j.gloenvcha.2008.04.010.

Tiwari, A. K., Shahbaz, M., \& Hye, Q. M. A. (2013). The environmental Kuznets curve and the role of coal consumption in India: Cointegration and causality analysis in an open economy. Renewable and Sustainable Energy Reviews, 18, 519-527. doi.org/10.1016/ j.rser.2012.10.031.

United Nations Environment Programme (UNEP). (2012). A guidebook to the green economy. Division for sustainable development, UNEP.

Van Rossem, R. (1996). The world system paradigm as general theory of development: A crossnational test. American Sociological Review, 61(3), 508-527. doi.org/10.2307/2096362.

Wang, P., Wanshui, W., Zhu, B. \& Wei, Y. (2013). Examining the impact factors of energyrelated $\mathrm{CO}_{2}$ emissions using the STIRPAT model in Guangdong Province, China. Applied Energy, 106, 65-71. doi.org/10.1016/j.apenergy.2013.01.036.

World Bank. (2013). World development indicators [data set]. Retrieved from data.worldbank. org/data-catalog/world-development-indicators.

York, R. (2004). The treadmill of (diversifying) production. Organization \& Environment, 17(3), 355-362.

York, R. (2006). Ecological paradoxes: William Stanley Jevons and the paperless office. Human Ecology Review, 13(2), 143.

York, R. (2012). Asymmetric effects of economic growth and decline on CO2 emissions. Nature Climate Change, 2(11), 762-764. doi.org/10.1038/nclimate1699.

York, R., \& Ergas, C. (2011). Women's status and world-system position: An exploratory analysis. Journal of World-Systems Research, 17(1), 147-164. doi.org/10.5195/jwsr. 2011.424 .

York, R., \& McGee, J. (2017). Does renewable energy development decouple economic growth from $\mathrm{CO}_{2}$ emissions? Socius, 3. doi.org/10.1177/2378023116689098.

York, R., \& Rosa, E. A. (2003). Key challenges to ecological modernization theory: Institutional efficacy, case study evidence, units of analysis, and the pace of eco-efficiency. Organization \& Environment, 16(3), 273-288. doi.org/10.1177/1086026603256299.

York, R., Rosa, E. A., \& Dietz, T. (2003a). Footprints on the earth: The environmental consequences of modernity. American Sociological Review, 68(2), 279-300. doi.org/ $10.2307 / 1519769$. 
York, R., Rosa, E. A., \& Dietz, T. (2003b). STIRPAT, IPAT and ImPACT: Analytic tools for unpacking the driving forces of environmental impacts. Ecological Economics, 46(3), 351-365. doi.org/10.1016/s0921-8009(03)00188-5.

York, R., Rosa, E. A., \& Dietz, T. (2003c). A rift in modernity? Assessing the anthropogenic sources of global climate change with the STIRPAT model. International Journal of Social Policy, 23, 31-51. doi.org/10.1108/01443330310790291.

York, R., Rosa, E. A., \& Dietz, T. (2010). Ecological modernization theory: Theoretical and empirical challenges. In M. R. Redclift \& G. Woodgate (Eds.), The international handbook of environmental sociology (pp. 77-90). Cheltenham, UK: Edward Elgar Publishing Limited. doi.org/10.4337/9781849805520.00014. 
This text is taken from Human Ecology Review, Volume 25, Number 1, 2019, published by ANU Press, The Australian National University, Canberra, Australia. doi.org/10.22459/HER.25.01.2019.03 